\title{
Farklı Kızılcık Genotiplerinin (Cornus mas L.) Yarı-Odun Çelikleri İle Çoğaltılma Olanakları
}

\author{
Mehmet Fikret BALTA ${ }^{1}$, İbrahim Ulvi EROL ${ }^{2}$, Orhan KARAKAYA ${ }^{3}$, Fikri BALTA ${ }^{4}$ \\ 1, 2, 3,4 Ordu Üniversitesi, Ziraat Fakültesi, Bhaçe Bitkileri Bölümü, Ordu, Türkiye, \\ ${ }^{1}$ https://orcid.org/0000-0002-3859-6490, ${ }^{2}$ https://orcid.org/0000-0001-9898-4180, ${ }^{3}$ https://orcid.org/0000-0003-0783-3120 \\ ${ }^{4} \mathrm{https}$ ://orcid.org/0000-0003-4414-8501 \\ $\triangle$ : fikret_balta@hotmail.com
}

\section{ÖZET}

Çalışma, farklı kızılcık genotipleri (21, 22, 24, 25 ve 44-05) ve Erolbey77 çeşidinin yarı-odun çelikleri ile çoğaltılma olanaklarının belirlenmesi amacı ile yürütülmüştür. İncelenen kızılcık genotiplerine ait yarı-odun çelikleri 15 Temmuz 2014 tarihinde alınmıştır. Hazırlanan çelikler iki gruba ayrılarak, yarısına herhangi bir uygulama yapılmamış (kontrol grubu), diğer yarısına ise 4000 ppm indol 3-butirik asit (IBA) uygulaması yapılmıştır. Köklendirme ortamına dikimden 5 hafta sonra sökülen çeliklerde köklenme oranı, kallüslenme oranı, en uzun ve en kısa kök boyu, yaşayan çelik oranı, kök dallanması ve köklenme kalitesi parametreleri incelenmiştir. Incelenen kızılcık genotiplerinde kontrol uygulamasinda köklenmenin meydana gelmediği tespit edilmiştir. IBA uygulanan yarı־odun çeliklerinde köklenme oranı \%0.0 (21) ile \%40.0 (25), kök sayısı 0.0 adet çelik $^{-1}$ (21) ile 1.93 adet çelik $^{-1}$ (Erolbey-77), kallüslenme oranı \%33.3 (44-05) ile \%86.6 (22), en uzun kök boyu $0.0 \mathrm{~mm}$ (21) ile $3.86 \mathrm{~mm}$ (25), en kısa kök boyu $0.0 \mathrm{~mm}$ (21) ile $1.27 \mathrm{~mm}$ (Erolbey-77) ve köklenme kalitesi 0.0 (21) ile 0.35 (25) arasında belirlenmiştir. Sonuç olarak, köklenme oranı, köklenme kalitesi ve diğer köklenme özellikleri bakımından genel olarak 25 nolu genotip diğer genotiplere göre daha iyi sonuçlar vermiştir.
Araştırma Makalesi

\author{
Makale Tarihçesi \\ Geliş Tarihi : 01.07.2020 \\ Kabul Tarihi : 20.08.2020
}

Anahtar Kelimeler

Kizılcık

Genetik kaynak

Köklenme

Kallüslenme

indol-3 bütirik asit

\section{Propagation Possibilites With Semi-Hardwood Cuttings of Different Cornelian Cherry Genotypes (Cornus mas L.)}

\section{ABSTRACT}

This study was conducted to determine propagation possibilites with semi-hardwood cuttings of different cornelian cherry genotypes (21, 22, 24, 25 ve 44-05) and Erolbey-77 cultivar. Semi-hardwood cuttings took from cornelian cherry genotypes investigated on 15 July, 2014. Prepared cuttings were divided into two groups. First group was left untreated (control teratment), the other group was treated with 4000 ppm dose of indole-3 butyric acid. After five weeks of growing, cuttings were removed from the rooting media and rooting ratio, callus ratio, number of roots, longest root lenght, shortest root lenght, living cutting ratio, number of lateral roots and rooting quality were determined. Rooting ratio, number of roots, callus ratio, longest root lenght, shortest root lenght and rooting quality in the semi-harwood cuttings applied IBA were determined from $0.0 \%$ (21) to $40.0 \%$ (25), 0.0 (21) to 1.93 number shoot ${ }^{-1}$ (Erolbey-77), 33.3\% (44-05) to $86.6 \%$ (22), $0.0 \mathrm{~mm} \mathrm{(21)} \mathrm{to} 3.86 \mathrm{~mm}$ (25), $0.0 \mathrm{~mm}$ (21) to $1.27 \mathrm{~mm}$ (Erolbey77) and $0.0(21)$ ile 0.35 (25), respectively. Consequently, the 25 genotype sustaned better results in terms of rooting ratio, rooting quality and other rooting properties than other genotypes.

\section{Research Article}

$\begin{array}{ll}\text { Article History } & \\ \text { Received } & : 01.07 .2020 \\ \text { Accepted } & : 20.08 .2020\end{array}$

Keywords
Cornelian Cherry
Genetic resource
Rooting
Callusing
Indole- 3 butyric acid

\footnotetext{
Atıf İçin: Balta MF, Erol İU, Karakaya O, Balta F 2020. Farklı Kızılcık Genotiplerinin (Cornus mas L.) Yarı-Odun Çelikleri İle Çoğaltılma Olanakları. KSÜ Tarım ve Doğa Derg 24 (4): 777-783. DOIः 10.18016/ ksutarimdoga.vi. 760930.

To Cite: Balta MF, Erol IUU, Karakaya O, Balta F 2020. Propagation Possibilites With Semi-Hardwood Cuttings of Different Cornelian Cherry Genotypes (Cornus mas L.). KSU J. Agric Nat 24 (4): 777-783. DOI: 10.18016/ ksutarimdoga.vi.760930.
} 


\section{GİṘŞ}

Kızılcık Cornaceae familyasının, Cornus cinsi içerisinde yer almakta olup, bu cinsin dünya üzerinde yayılış gösteren yaklaşık 65 türü bulunmaktadır (Hosseinpour-Jaghdani ve ark., 2017). Bu türlerden en önemlisi Cornus mas L. olup, meyve kalitesinin iyi olması nedeni ile ticari kızılcık yetiştiriciliğinde kullanılmaktadır (Seeram ve ark., 2002). Kızılcık dünya üzerinde Türkiye, Balkanlar, Kafkasya ve Akdeniz Havzası'nın da içinde bulunduğu Güneybatı Asya, Orta ve Güneydoğu Avrupa'da doğal olarak yayılış göstermektedir (Ercişli 2004; D'Antuono ve ark., 2014). Bu bölgelerde kızılcığın çoğunlukla tohumdan çoğaltılması dolayısıyla zengin bir genetik çeşitlilik ortaya çıkmıştır (Yılmaz ve ark., 2009; Mranitic ve ark., 2015).

Dünya kızılcık üretimi yaklaşık 723 bin tondur. Kızılcık üretim miktarı bakımından Amerika Birleşik Devletleri (404 880 t) ilk sirada yer almakta olup, bu ülkeyi sırası ile Kanada (195 196 t), Şili (106 180 t), Türkiye (11 481 t) ve Azerbaycan (2 874 t) izlemektedir (Anonim, 2020a). Ülkemiz dünya kızılcık üretiminde ilk sıralarda yer almasına karşın, kızılcık üretimdeki payı yaklaşık \%1.6'dır. Türkiye'de kızılcık üretimi bakımından Samsun (1 243 t), Bolu (1 225 t), Bartın (847 t), Erzurum (594 t) ve Balıkesir (570 t) illeri öne çıkmaktadır (Anonim, 2020b).

Kızılcık insan sağlığını teşvik eden maddelerce zengin olup, günümüzde tıp alanında kullanılmaktadır (Hassanpour ve ark., 2011). Son ylllarda insanlarm doğal antioksidan kaynağı olan meyve türlerine olan talebinin artmasından dolayı kızılcık yetiştiriciliği artış göstermiştir (Gunduz ve ark., 2013; Bijelik ve ark., 2012). Bu bakımdan ülkemizin dünya kızılcık üretimindeki payının arttırılması ve ekonomik gelir sağlanması açısından kızılcık ile kurulacak kapama bahçelerin sayısının arttırılması önem arz etmektedir. $\mathrm{Bu}$ nedenle ülkemizde kızılcık üzerine yapılan seleksiyon ıslahı çalışmaları neticesinde seçilen genotiplerin ve standart kızılcık çeşitlerinin çoğaltılma olanaklarının belirlenmesi, kızılcık meyve türü ile kurulacak kapama bahçelerin fidan ihtiyacının karşılanması bakımından önemlidir (Balta ve ark., 2019).

Kızılcık tohum (Pırlak, 1997a; Hocoğlu, 2013), aşı (Kalkışım, 1997), çelik (Ivanicka ve Cvopa, 1997; Yavaş, 2000; Kalyoncu ve ark., 2008; Markovic ve ark., 2013, Yavuz, 2015; Balta ve ark., 2019) ve doku kültürü (Ayan ve Feyzioğlu, 2002; Durkovic, 2008) ile çoğaltılabilmektedir. Bu yöntemlerden çelik ile çoğaltma kızılcığın çoğaltılmasında en fazla kullanılan yöntemlerden biridir. Basit ve ucuz bir yöntem olan çelik ile çoğaltma köklenme kabiliyeti yüksek olan bazı meyve türlerinin çoğaltılmasında yaygın olarak kullanılmaktadır. Kızılcıkta yeşil, yarı-odun ve odun çelikleri kullanılarak yapılan çoğaltma çalışmalarında köklenme oranının düşük olduğu ve hormon uygulamasının köklenme oranını $\operatorname{artırdığ~}$ bildirilmiştir (Prrlak, 1997b; Markovic ve ark., 2013, Balta ve ark., 2019). Bunun yanı sira erken haziran çeliklerinin kızılcıkta köklenmeyi önemli ölçüde teşvik ettiği belirtilmektedir (Kalyoncu ve Ecevit, 1995). Kızılcık üzerine yapılan çoğaltma çalışmalarında yeşil çelikler için 3500 ppm (Yavuz, 2015), yarı-odun çelikleri için 4000 ppm (Pırlak, 1997b) ve odun çelikleri için 6000 ppm (Pırlak, 2000) IBA dozlarının köklenmeyi teşvik etmek için ideal konsantrasyonlar olduğu bildirilmiştir.

Çeliklerde köklenme üzerine etki eden içsel (genetik yapı, hormanlar, depo maddeleri vb.) (Hartmann ve ark., 2011) ve dışsal (sıcaklık, nem, ışık, köklendirme ortamı, çelik alma zamanı) birçok faktör bulunmaktadır (Ağaoğlu ve ark., 2019). Bu faktörlerin çeliklerde köklenme oranı, köklenme kalitesi ve köklenme özelliklerini önemli derecede etkilediği (Ağaoğlu ve ark., 2019) ve indol-3 bütirik asit (IBA)'in çeliklerde adventif kök oluşumunun teşvik edilmesi bakımından en iyi bitki büyüme düzenleyici olduğu belirtilmektedir (Kaşka ve Yılmaz, 1974).

$\mathrm{Bu}$ çalışma farklı kızılcık genotipleri ve Erolbey-77 kızılcık çeşidinin yarı odun çelikleri ile çoğaltılma olanaklarının belirlenmesi amacı ile yürütülmüştür.

\section{MATERYAL ve METOD}

\section{Materyal}

Çalışmanın materyalini Malatya Meyvecilik Araştırma Enstitüsü bünyesinde yürütülen 'Kızılcık Genetik Kaynaklarının Toplanması, Muhafazası ve Değerlendirilmesi' projesi kapsamından seçilen 5 kızılcık genotipi $(21,22,24,25$ ve 44-05) ile, Erolbey77 kızılcık çeşidi oluşturmuştur. Kızılcık genotiplerine ait çeliklerin köklendirilmesi için Malatya Meyvecilik Araştırma Enstitüsü bünyesindeki çoğaltma seraları kullanılmıştır.

\section{Metod}

İncelenen kızılcık çeşit ve genotiplerine ait 7 yaşh bitkilerde 15 Şubat 2014 tarihinde sert budama yapılmıştır. Budama yapılan kızılcık bitkilerinin yıllık sürgünlerinden yumuşak odunlaşmanın başladığ noktanın 20-25 cm üzerinden 15 Temmuz 2014 tarihinde çelik alma işlemi yapılmıştır. Alınan çeliklerde hem yaprak hem de göz olmasına dikkat edilmiştir. Çelikler nem kaybının olmaması için nemli bezlere sarılarak, gölge bir ortama transfer edilmiştir. Alınan çelikler 15-20 cm boyunda olacak şekilde hazırlanmış ve çeliğin en uçtaki bir veya iki yaprak çifti hariç diğer yapraklar kesilerek uzaklaştırılmışır. Hazırlanan çelikler iki gruba ayrılarak, yarısına herhangi bir uygulama yapılmamış (kontrol grubu), diğer yarısına ise $4000 \mathrm{ppm}$ indol 3-butirik asit (IBA) uygulaması yapılmıştır. IBA dozunun seçiminde 
Pırlak (1997b)'ın kızılcıkta yeşil ve yarı-odun çeliklerini kullanarak yaptığı çalışmanın sonuçları dikkate alınmıştır. Uygulama yapılan çelikler 2/3'lük kısmı köklendirme ortamında kalacak şekilde köklendirme tavalarına dikilmiştir. Köklendirme ortamı olarak iri tarım perliti $(0.0-0.5 \mathrm{~mm})$ kullanılmıştır. Köklendirme ortamının nem içeriği $\% 85-90$ ve sicaklığ 1 ise $18-20^{\circ} \mathrm{C}$ olacak şekilde ayarlanmıştır. Köklendirme ortamının nem içeriğinin sağlanması için mistleme ünitesi kullanılmıştır.

Çalışma tesadüf parselleri deneme desenine göre 4 tekerrürlü ve her tekerrürde 15 bitki olacak şekilde planlanmıştır. Köklendirme ortamına dikilen çeliklerde 5 hafta sonra söküm işlemi gerçekleştirilmiş ve köklenme oranı, kallüslenme oranı, en uzun ve en kısa kök boyu, kök dallanması, yaşayan çelik oranı ve köklenme kalitesi özellikleri belirlenmiştir.

Köklenme oranı (\%): Köklenen çeliklerin sayılarak, tüm çeliklere oranlaması ile belirlenmiştir (Kalyoncu, 1996; Kalyoncu ve ark., 2008).

Kallüslenme oranı (\%): Kallüslenmenin gerçekleştiği çeliklerde gözlem yolu ile belirlenmiş ve \% olarak ifade edilmiştir (Kalyoncu, 1996; Kalyoncu ve ark., 2008).

En uzun $(\mathrm{mm})$ ve en kisa kök boyu $(\mathrm{mm})$ : Köklenen çeliklerde en uzun ve en kısa kök boyu 0.01 mm'ye duyarlı dijital kumpas (Mitutoyo, Japonya) yardımıyla ölçülmüştür (Kalyoncu, 1996; Kalyoncu ve ark., 2008).

Kök dallanması (adet çelik-1): Kök dallanması meydana gelen çeliklerde sayım yapılarak belirlenmiştir (Kalyoncu, 1996; Kalyoncu ve ark., 2008).

Yaşayan çelik oranı (\%): İncelenen kızılcık çeşit ve genotiplerinde ölü çeliklerin sayısının yaşayan çelik sayısına oranlanmasıyla tespit edilmiştir (Kalyoncu, 1996; Kalyoncu ve ark., 2008).

Köklenme kalitesi: Köklenen çeliklerde 1-3 skalasına (1-zayıf, 2-orta, 3-iyi) göre değerlendirme yapılarak belirlenmiştir (Pırlak, 1997b).

\section{İstatistiksel analiz}

İncelenen kızılcık çeşit ve genotipleri arasında köklenme özellikleri bakımından görülen farklılıklar Tukey çoklu karşılaştırma yöntemi kullanılarak, \%5 önem seviyesinde belirlenmiştir. \% olarak ifade edilen özelliklere ait değerlerin istatistiksel analizinde açı transformasyonu uygulanmıştır. İstatistiksel analizler için Minitab 17 istatistik paket programı kullanılmıştır.

\section{BULGULAR ve TARTIŞMA}

\section{Köklenme Oranı (\%)}

Köklenme oranı bakımından IBA uygulanmış kızılcık çeşit ve genotipleri arasında istatistiksel olarak önemli farklılıklar $(\mathrm{p}<0.05)$ belirlenirken, herhangi bir uygulamanın yapılmadığı kontrol konusunda ise köklenmenin olmadiğ 1 görülmüştür. IBA uygulamasında köklenme oranı \%0.0 (21 nolu genotip) ile \%40.0 (25 nolu genotip) arasında değişiklik göstermiştir. Bunun yanı sıra IBA uygulamasında köklenme oranı bakımından 25 nolu genotip ve 44-05 nolu genotip ile Erolbey- 77 çeşidi ve 22 nolu genotip ile 24 nolu genotip istatistiksel olarak aynı grupta yer almıştır (Çizelge 1). Pırlak (1997b) farklı kızılcık genotiplerine ait yarı odun çelikleri ile yaptığ çalışmada köklenme oranının genotiplere bağlı olarak değişiklik gösterdiğini ve kontrol uygulamasına kıyasla (\%0.0-5.0) en iyi köklenmenin 4000 ppm IBA uygulamasında (\%30-60) olduğunu belirlemiştir. Yine kızılcık yarı-odun çelikleri kullanılarak yapılan çoğaltma çalışmalarında benzer sonuçlar rapor edilmiştir (Yavaş, 2000; Yavuz, 2015). Mevcut çalışmada da köklenme oranı üzerine genotipin ve hormon uygulamassnın önemli bir etkisinin olduğu belirlenmiştir. Bunun yanı sıra 25, 44-05 genotipleri ile Erolbey-77 çeşidinin köklenme oranının araştırıcıların bulguları ile benzerlik gösterdiği, diğer genotiplerin ise köklenme oranının düşük olduğu tespit edilmiştir. Görülen farklılıkların genetik yapıdan (Hartmann ve ark., 2011) ve çeliklerin bitki üzerinden alındığı yerden (Yıldız ve ark., 2009) kaynaklanabileceği ifade edilebilir. Nitekim, çeliklerde kök oluşumu üzerine genetik yapının, hormanların, depo maddelerinin (Hartmann ve ark., 2011; Azad ve ark., 2016) sicaklık, nem, ışık, köklendirme ortamı (Ağaoğlu ve ark., 2019), çelik alma zamanı, çelik yaşı ve çeliğin bitki üzerinden alındığı yerin önemli bir etkisi bulunmaktadır (Yıldız ve ark., 2009).

\section{Kök Sayısı (adet çelik ${ }^{-1}$ )}

Kök sayısı, çeliklerde köklenme kalitesi ve sonraki aşamada fidan kalitesini etkileyen önemli bir özelliktir (Yıldız ve ark., 2009). Çeliklerde kök sayısı üzerine genetik yapı, çelik yaşı (Azad ve Matin, 2015) ve hormonlar (Cristofori ve ark., 2010) etki etmektedir.

İncelenen kızılcık çeşit ve genotiplerinde kök sayısı bakımından yalnızca IBA uygulamasında önemli farklılıklar $\quad(\mathrm{p}<0.05)$ tespit edilmiştir. IBA uygulamasında kök sayısı 0.0 adet çelik ${ }^{-1}$ (21 nolu genotip) ile 1.93 adet çelik ${ }^{-1}$ (Erolbey-77) arasında belirlenmiştir. 25 nolu genotip ve 44-05 nolu genotip kök sayısı bakımından Erolbey-77 çeşidi ile istatistiksel olarak benzer grupta yer almıştır (Çizelge 1). Kök sayısını Yavaş (2000) kızılcık yarı-odun çeliklerinde kontrol grubunda 52.80 adet çelik ${ }^{-1}$ ve 3500 ppm IBA uygulamasında ise 135.20 adet çelik ${ }^{-1}$ olarak belirlemiştir. Bunun yanı sıra kızılcıkta yeşil çelik kullanılarak yapılan çalışmalarda kök sayının genetik yapıya bağlı olarak değiştiği (Balta ve ark., 2019) ve kök sayısı üzerine IBA uygulamasının önemli bir etkisinin olduğu bildirilmiştir (Kalyoncu ve Ecevit, 1995; Kalyoncu ve ark., 2008; Balta ve ark., 2019). 
Çalışmada da kök sayısı üzerine genetik yapının ve hormon uygulamasının önemli bir etkisi belirlenmiştir. Araştırıcıların bulguları ile kıyaslandığında incelenen genotiplere ait kök sayısı değerlerinin düşük olduğu tespit edilmiştir. Yürütülen çalışmalarda dikkate alındığında bu durumun genetik yapıdaki farklılıklardan (Azad ve Matin, 2015) kaynaklı olabileceği düşünülmektedir.

Çizelge 1. Kızılcık genotiplerinin köklenme oranı (\%) ve kök sayısı (adet çelik-1)

Table 1. Rooting ratio (\%) and number of root of (number cutting ${ }^{-1}$ ) cornelian cherry genotypes

\begin{tabular}{|c|c|c|c|c|}
\hline \multirow{2}{*}{$\begin{array}{l}\text { Genotipler } \\
\text { Genotypes }\end{array}$} & \multicolumn{2}{|c|}{$\begin{array}{l}\text { Köklenme Oranı (\%) } \\
\text { Rooting Ratio (\%) }\end{array}$} & \multicolumn{2}{|c|}{$\begin{array}{l}\text { Kök Sayısı (adet çelik-1) } \\
\text { Number of Roots (number cutting-1) }\end{array}$} \\
\hline & Kontrol & $4000 \mathrm{ppm}$ & Kontrol & $4000 \mathrm{ppm}$ \\
\hline 21 & $0 \pm 0.0$ & $0.0 \pm 0.0 \mathrm{c}$ & $0 \pm 0.0$ & $0.0 \pm 0.0 \mathrm{c}$ \\
\hline 22 & $0 \pm 0.0$ & $13.33 \pm 1.53 \mathrm{~b}$ & $0 \pm 0.0$ & $0.73 \pm 0.29 \mathrm{ab}$ \\
\hline 24 & $0 \pm 0.0$ & $6.67 \pm 2.08 \mathrm{~b}$ & $0 \pm 0.0$ & $0.20 \pm 0.13 \mathrm{~b}$ \\
\hline 25 & $0 \pm 0.0$ & $40.00 \pm 6.24 \mathrm{a}$ & $0 \pm 0.0$ & $0.80 \pm 0.13 \mathrm{ab}$ \\
\hline $44-05$ & $0 \pm 0.0$ & $33.33 \pm 8.14 \mathrm{a}$ & $0 \pm 0.0$ & $1.33 \pm 0.57 \mathrm{ab}$ \\
\hline Erolbey-77 & $0 \pm 0.0$ & $33.33 \pm 6.11 \mathrm{a}$ & $0 \pm 0.0$ & $1.93 \pm 0.90 \mathrm{a}$ \\
\hline
\end{tabular}

Aynı sütünda aynı harf ile gösterilen ortalamalar arasındaki farklılık önemsizdir $(\mathrm{p}<0.05)$

\section{Kallüslenme Oranı (\%)}

Kallüslenme oranı çeliklerde köklenme oranı etkileyen önemli bir özelliktir (Kalyoncu ve ark., 2008). İncelenen kızılcık çeşit ve genotiplerinde kallüslenme oranı bakımından önemli farklılıklar belirlenmiştir $(\mathrm{p}<0.05)$. Kallüslenme oranı kontrol grubunda $\% 40.0$ (44-05) ile \%100 (24) arasında tespit edilmiştir. 24 nolu genotipin diğer genotiplere kıyasla belirgin bir şekilde daha yüksek kallüslenme oranına sahip olduğu belirlenmiştir. IBA uygulamasında ise kallüslenme oranı \%33.3 (44-05) ile \%86.6 (22) arasında belirlenmiştir. 22 nolu genotip diğer genotiplere göre önemli derecede daha yüksek kallüslenme oranına sahip olmuştur (Çizelge 2).

Kızılcık ile yapılan çoğaltma çalışmalarında genotipe bağlı olarak kallüslenme oranının önemli ölçüde değiştiği (Pırlak, 1997b; Yavuz, 2015) ve kontrol grubu çeliklerinde kallüslenme oranının IBA uygulanmış çeliklere göre daha yüksek olduğu belirlenmiştir (Kalyoncu ve ark., 2008; Balta ve ark., 2019). Nitekim, Markovic ve ark., (2013) kızılcık yarı-odun çeliklerinde kallüslenme oranını kontrol uygulamasında \%73.3 olarak belirlerken, IBA uygulamasında ise \%33.3 olarak tespit etmişlerdir. Mevcut çalışmada da kallüslenme oranı bakımından genotipler arasında önemli farklılıkların olduğu ve IBA uygulanmış çeliklerde kallüslenme oranının kontrol çeliklerine göre daha düşük olduğu belirlenmiştir. Bu durum, hormon uygulamasının çeliklerde kallüs oluşumunu azaltması ve buna bağlı olarak kök oluşumunu arttırması ile ilişsili olabilir (Kalyoncu, 1996).

Çizelge 2. Kızılcık genotiplerinin kalluslenme ve yaşayan çelik oranı (\%)

Table 2. Callus and survival cutting ratio (\%) of cornelian cherry genotypes

\begin{tabular}{lllll}
\hline \multirow{2}{*}{$\begin{array}{l}\text { Genotipler } \\
\text { Genotypes }\end{array}$} & \multicolumn{2}{l}{$\begin{array}{l}\text { Kalluslenme Oranı (\%) } \\
\text { Callus Ratio (\%) }\end{array}$} & \multicolumn{2}{l}{$\begin{array}{l}\text { Yaşayan Çelik Oranı (\%) } \\
\text { Survival Cutting Ratio (\%) }\end{array}$} \\
\cline { 2 - 5 } & Kontrol & $4000 \mathrm{ppm}$ & Kontrol & $4000 \mathrm{ppm}$ \\
\hline 21 & $80 \pm 5.0 \mathrm{~b}$ & $53.3 \pm 6.81 \mathrm{bc}$ & $100 \pm 0.0$ & $100 \pm 0.0$ \\
22 & $60 \pm 4.36 \mathrm{c}$ & $86.6 \pm 6.11 \mathrm{a}$ & $100 \pm 0.0$ & $100 \pm 0.0$ \\
24 & $100 \pm 0.0 \mathrm{a}$ & $53.3 \pm 5.51 \mathrm{bc}$ & $100 \pm 0.0$ & $100 \pm 0.0$ \\
25 & $80 \pm 4.58 \mathrm{~b}$ & $66.6 \pm 3.21 \mathrm{ab}$ & $100 \pm 0.0$ & $100 \pm 0.0$ \\
$44-05$ & $40 \pm 9.54 \mathrm{~d}$ & $33.3 \pm 10.02 \mathrm{c}$ & $100 \pm 0.0$ & $100 \pm 0.0$ \\
Erolbey-77 & $60 \pm 7.0 \mathrm{c}$ & $46.6 \pm 12.86 \mathrm{bc}$ & $100 \pm 0.0$ & \\
\hline
\end{tabular}

Aynı sütünda aynı harf ile gösterilen ortalamalar arasındaki farklılık istatistiksel olarak önemsizdir $(\mathrm{p}<0.05)$

\section{Yaşayan Çelik Oranı (\%)}

Yaşayan çelik oranı üzerine çeliklerde bulunan doğal oksin içeriği (Baul ve ark., 2010) ve kallüs oluşumu etki etmektedir (Kalyoncu, 1996). Bunun yanı sıra özellikle yeşil ve yarı-odun çelikleri kullanılarak yapılan çoğaltma çalışmalarında ortam neminde meydana gelebilecek nem kayılarının minimum düzeyde tutulması yaşayan çelik oranının yüksek olması açısından önemli olduğu ifade edilmektedir (Kamaluddin ve Ali, 1996).
Mevcut çalışmada yaşayan çelik oranı bakımından her iki uygulamada da incelenen kızlcık genotipleri arasındaki farklılık önemsiz bulunmuştur $(p>0.05)$. İncelenen kızılcık çeşit ve genotiplerinde yaşayan çelik oranı hem kontrol grubunda hem de IBA uygulamasında \%100 olarak belirlenmiştir (Çizelge 2). Pırlak (1997b) yaşayan çelik oranı üzerine hormon uygulamasının etkili olduğunu ve genotipe bağh olarak yaşayan çelik oranının farklılık gösterdiğini bildirirken, farklı araştırıcılar kızılcıkta yaşayan çelik 
oranı üzerine hormon uygulamasının önemli bir etkisinin olmadığını ve tüm uygulamalarda yaşayan çelik oranının \%100 olduğunu bildirilmişlerdir (Kalyoncu ve ark., 2008; Balta ve ark., 2019). Nitekim mevcut çalışmada da yaşayan çelik oranı üzerine genotipin ve hormon uygulamasının önemli bir etkisinin olmadığı tespit edilmiştir.

\section{En Uzun ve En Kisa Kök Boyu (mm)}

Kök uzunluğu, köklenen çeliklerde köklenme kalitesinin belirlenmemesinde kullanılan önemli bir özelliktir (Yıldız ve ark., 2009). İncelenen kızılcık çeşit ve genotiplerinde en uzun kök boyu ve en kısa kök boyu bakımından yalnızca IBA uygulamasında önemli farklılıklar $\quad(p<0.05)$ tespit edilmiştir. IBA uygulamasinda en uzun kök boyu $0.0 \mathrm{~mm}$ (21 nolu genotip) ile $3.86 \mathrm{~mm}$ (25 nolu genotip) arasinda ölçülmüştür. En uzun kök boyu bakımından 25 nolu genotip ile Erolbey-77 çeşidi, 22 nolu genotip ve 24 nolu genotip ile 44-05 nolu genotip istatistiksel olarak aynı grupta yer almıştır. IBA uygulamasında en kısa kök boyu $0.0 \mathrm{~mm}$ (21 nolu genotip) ile $1.27 \mathrm{~mm}$
(Erolbey-77) arasında ölçülmüştür. En kısa kök boyu bakımından en yüksek değere sahip Erolbey-77 çeşidi ile 25 nolu genotip ve 44-05 nolu genotip istatistiksel olarak benzer grupta yer almıştır (Çizelge 3).

Yavuz (2015) kızılcıkta yarı-odun çeliklerini kullanarak yürüttüğü çalışmada kök uzunluğunun genotipe bağlı olarak değişiklik gösterdiğini ve kök uzunluğunun kontrol uygulamasinda 2.48-4.10 mm, 3500 ppm IBA uygulamasinda ise $8.50-14.00 \mathrm{~mm}$ arasında değiştiğini belirlemiştir. Yine kızılcık ile yapılan farklı çalışmalarda kök uzunluğu üzerine hormon uygulamasının (Pırlak, 1997b; Markovic ve ark., 2013) önemli bir etkisinin olduğu ve kök uzunluğunun genetik yapıya (Balta ve ark., 2019) bağlı olarak değiştiği rapor edilmiştir. Mevcut çalışmada da benzer sonuçlar elde edilirken, kök uzunluğuna ait değerlerin ise araştırıcıların bulgularından düşük olduğu belirlenmiştir. Bu durumun genetik yapı (Balta ve ark., 2019) ve çeliklerde bulunan doğal oksin miktarı (Husen ve Pal, 2006; Baul ve ark., 2010) ile ilişkili olduğu düşünülmektedir.

Çizelge 3. Kızılcık genotiplerinin en uzun ve en kısa kök boyu (mm)

Table 3. Longest and shortest root lenght $(\mathrm{mm})$ of cornelian cherry genotypes

\begin{tabular}{|c|c|c|c|c|}
\hline \multirow{2}{*}{$\begin{array}{l}\text { Genotipler } \\
\text { Genotypes }\end{array}$} & \multicolumn{2}{|c|}{$\begin{array}{l}\text { En Uzun Kök Boyu (mm) } \\
\text { Longest Root Lenght ( } \mathrm{mm})\end{array}$} & \multicolumn{2}{|c|}{$\begin{array}{l}\text { En Kısa Kök Boyu (mm) } \\
\text { Shortest Root Lenght ( } \mathrm{mm})\end{array}$} \\
\hline & Kontrol & $4000 \mathrm{ppm}$ & Kontrol & $4000 \mathrm{ppm}$ \\
\hline 21 & $0 \pm 0.0$ & $0.0 \pm 0.0 \mathrm{c}$ & $0 \pm 0.0$ & $0.0 \pm 0.0 \mathrm{c}$ \\
\hline 22 & $0 \pm 0.0$ & $0.77 \pm 0.14 \mathrm{~b}$ & $0 \pm 0.0$ & $0.37 \pm 0.18 \mathrm{ab}$ \\
\hline 24 & $0 \pm 0.0$ & $0.20 \pm 0.09 \mathrm{~b}$ & $0 \pm 0.0$ & $0.13 \pm 0.13 \mathrm{~b}$ \\
\hline 25 & $0 \pm 0.0$ & $3.86 \pm 0.52 \mathrm{a}$ & $0 \pm 0.0$ & $1.15 \pm 0.49 \mathrm{ab}$ \\
\hline $44-05$ & $0 \pm 0.0$ & $1.29 \pm 0.34 \mathrm{~b}$ & $0 \pm 0.0$ & $0.61 \pm 0.33 \mathrm{ab}$ \\
\hline Erolbey-77 & $0 \pm 0.0$ & $3.15 \pm 0.93 \mathrm{a}$ & $0 \pm 0.0$ & $1.27 \pm 0.64 \mathrm{a}$ \\
\hline
\end{tabular}

Aynı sütünda aynı harf ile gösterilen ortalamalar arasındaki farklılık istatistiksel olarak önemsizdir $(\mathrm{p}<0.05)$

\section{Köklenme Kalitesi}

Köklenme kalitesi kök oluşumunun meydana geldiği çeliklerin fidan kalitesini etkileyen önemli bir özelliktir (Yıldız ve ark., 2009). Köklenme kalitesi bakımından incelenen kızılcık çeşit ve genotipleri arasinda yalnızca IBA uygulamasinda önemli farklılıklar tespit edilmiştir $(\mathrm{p}<0.05)$. Incelenen kızılcık çeşit ve genotiplerinde köklenme kalitesi 0.0 (21 nolu genotip) ile 0.35 (25 nolu genotip) arasinda belirlenmiştir. Köklenme kalitesi bakımından 25 nolu genotip ve 44-05 nolu genotip Erolbey-77 çeşidi ile istatistiksel olarak aynı grupta yer almıştır (Çizelge 4).

Çizelge 4. Kızılcık genotiplerinin köklenme kalitesi ve kök dallanması

Table 4. Rooting quality and root branching of cornelian cherry genotypes

\begin{tabular}{|c|c|c|c|c|}
\hline \multirow{2}{*}{$\begin{array}{l}\text { Genotipler } \\
\text { Genotypes }\end{array}$} & \multicolumn{2}{|c|}{$\begin{array}{l}\text { Köklenme Kalitesi (1-3 skalası) } \\
\text { Rooting Quality (1-3 scale) }\end{array}$} & \multicolumn{2}{|c|}{$\begin{array}{l}\text { Kök Dallanması (adet çelik }{ }^{-1} \text { ) } \\
\text { Root Branching (number cutting-1) }\end{array}$} \\
\hline & Kontrol & 4000 ppm & Kontrol & $4000 \mathrm{ppm}$ \\
\hline 21 & $0 \pm 0.0$ & $0 \pm 0.0 \mathrm{~d}$ & $0 \pm 0.0$ & $0 \pm 0.0$ \\
\hline 22 & $0 \pm 0.0$ & $0.13 \pm 0.10 \mathrm{bc}$ & $0 \pm 0.0$ & $0 \pm 0.0$ \\
\hline 24 & $0 \pm 0.0$ & $0.06 \pm 0.03 \mathrm{c}$ & $0 \pm 0.0$ & $0 \pm 0.0$ \\
\hline 25 & $0 \pm 0.0$ & $0.35 \pm 0.05 \mathrm{a}$ & $0 \pm 0.0$ & $0 \pm 0.0$ \\
\hline $44-05$ & $0 \pm 0.0$ & $0.26 \pm 0.04 \mathrm{ab}$ & $0 \pm 0.0$ & $0 \pm 0.0$ \\
\hline Erolbey-77 & $0 \pm 0.0$ & $0.33 \pm 0.03 \mathrm{a}$ & $0 \pm 0.0$ & $0 \pm 0.0$ \\
\hline
\end{tabular}

Aynı sütünda aynı harf ile gösterilen ortalamalar arasındaki farklılık istatistiksel olarak önemsizdir $(p<0.05)$

Pırlak (1997b) kızılcıkta köklenme kalitesi üzerine hormon uygulamasının önemli bir etkisinin olduğunu ve uygulanan hormon dozu arttıkça köklenme kalitesinin de arttığını bildirmiştir. Benzer şekilde 
Balta ve ark. (2019) kızılcıkta köklenme kalitesinin hormon uygulaması ile arttığını ve genotipe bağlı olarak önemli ölçüde değişiklik gösterdiğini tespit etmişlerdir. Nitekim araştırıcılar farklı kızılcık genotiplerinde köklenme kalitesini kontrol uygulamasinda \%0.0-0.5 arasinda belirlerken, hormon uygulamasında 1.56-3.00 arasında belirlemişlerdir (Pırlak, 1997b; Balta ve ark., 2019). Mevcut çalışmada da benzer sonuçlar elde edilirken, köklenme kalitesine ait değerlerin ise araştırıcıların bulgularından düşük olduğu tespit edilmiştir. Bu durumun genetik yapıdaki farklılıklardan kaynaklı olabileceği ifade edilebilir.

\section{Kök Dallanması}

İncelenen kızılcık çeşit ve genotiplerinde kök dallanması meydana gelmemiştir (Çizelge 4). Kızılcık yarı-odun çeliklerinde kök dallanmasını, Pırlak (1997b) farklı kızılcık genotiplerinde kontrol uygulamasinda 0-2 adet ve $4000 \mathrm{ppm}$ IBA uygulamasinda 15-17 adet; Markovic ve ark. (2013) kontrol grubunda 5.5 adet, \%1'lik IBA uygulamasinda ise 6.5 adet olarak belirlemiştir. Bunun yanı sıra farklı araştırıcılar kızılcıkta yeşil çelik ile yapılan çoğaltma çalışmalarında kök dallanmasının olmadığını bildirmişlerdir (Kalyoncu ve ark., 2008; Balta ve ark., 2019). Benzer şekilde mevcut çalışmada da incelenen kızılcık genotiplerinde kök dallanmasının olmadığ belirlenmiştir. Görülen farklılıkların genetik yapıdan kaynaklı olabileceği ifade edilebilir.

\section{SONUÇ}

Farklı kızılcık genotipleri ve Erolbey-77 çeşidinin yarıodun çelikleri ile çoğaltılma olanaklarının araştırıldığg çalışmada, kızılcığın çelik ile çoğaltılması üzerine hormon uygulamasının önemli bir etkisinin olduğu ve köklenme özelliklerinin genetik yapıya bağlı olarak önemli ölçüde değişiklik gösterdiği belirlenmiştir. Köklenme oranı, köklenme kalitesi ve diğer köklenme özellikleri bakımından 25 nolu genotip diğer genotiplere ve Erolbey-77 çeşidine göre daha iyi sonuçlar vermiştir. Genel olarak değerlendirildiğinde incelenen kızılcık çeşit ve genotiplerinin yarı-odun çelikleri ile çoğaltılma olanaklarının sınırlı olduğu, bu nedenle incelenen genotiplerden farkl dönemlerde alınacak çeliklerin köklenme oranı ve kalitesi üzerine olumlu bir etkisinin olabileceği düşünülmektedir.

\section{Araştırmacıların Katkı Oranı Beyan Özeti}

Yazarlar makaleye eşit oranda katkı sağlamış olduklarını beyan eder.

\section{Çıkar Çatışması Beyanı}

Makale yazarları aralarında herhangi bir çıkar çatışması olmadığını beyan ederler.

\section{KAYNAKLAR}

Ağaoğlu YS, Çelik H, Çelik M, Fidan Y, Gülşen Y, Günay A, Halloran N, Köksal Aİ, Yanmaz R 2019. Genel Bahçe Bitkileri. Ankara Üniversitesi Basım Evi, Ankara, 319sy.

Anonim 2020a. Food and Agriculture Organization. http://www.fao.org/faostat/en/\#data/QC

Anonim 2020b. Bitkisel Üretim İstatistikleri. Türkiye İstatistik Kurumu. http://www.tuik.gov.tr/ PreTablo.do?alt_id=1001.

Ayan S, Feyzioğlu F 2002. Farklı Bitki Büyüme Düzenleyicilerinin Kızılcık (Cornus mas L.) Planlet Gelişimine Etkileri. Gazi Üniversitesi Dergisi 15(2): 533-556.

Azad M, Matin M 2015. Effect of Indole-3-butyric Acid on Clonal Propagation of Swietenia macrophylla through Branch Cutting. Journal of Botany 249308: 1-7.

Azad MS, Alam MJ, Mollick AS, Matin MA 2016. Responses of IBA on Rooting, Biomass Production and Survival of Branch Cuttings of Santalum album L. A Wild Threatened Tropical Medicinal Tree Species. Journal of Science Technology and Environment Informatics2(3): 195-206.

Balta MF, Erol İU, Özrenk K, Karakaya O, Uzun S 2019. Kızılcık (Cornus mas L.) Genotiplerinin Yeşil Çelik ile Çoğaltılması Üzerine Araştırmalar. Türkiye Tarımsal Araştırmalar Dergisi 6(2): 136141.

Baul TK, Mezbahuddin M, Hossain MM, Mohiuddin M 2010. Vegetative Propagation of Holarrhena pubescens, A Wild Tropical Medicinal Plant: Effect of Indole-3-Butyric Acid (IBA) on Stem Cuttings. Forestry Studies in China 12(4): 228-235.

Bijelić S, Gološin B, Ninić Todorović J, Cerović S, Bogdanović B 2012. Promising Cornelian Cherry (Cornus mas L.) Genotypes from Natural Population in Serbia. Agriculturae Conspectus Scientificus 77(1): 5-10.

Cristofori V, Rouphael Y, Rugini E 2010. Collection Time, Cutting Age, IBA and Putrescine Effects on Root Formation in Corylus avellana L. Cuttings. Scientia Horticulturae 124(2): 189-194.

D'Antuono LF, Kolesnov A, Fedosova K, Jorjadze M, Boyko N, Mudryk M, Bignami C 2014. Cornelian Cherry: An Important Local Resource and Promising Health Promoting Fruit Plant of the Black Sea Area. Acta Horticulturae 1017: 299-307.

Durkovič J 2008. Micropropagation of Mature Cornus mas 'Macrocarpa'. Trees 22 (4): 597-602.

Ercisli S 2004. A Short Review of The Fruit Germplasm Resources of Turkey. Genetic Resources and Crop Evolution 51(4): 419-435.

Gunduz K, Saracoglu O, Özgen M, Serce S 2013. Antioxidant, Physical and Chemical Characteristics of Cornelian Cherry Fruits (Cornus mas L.) at Different Stages of Ripeness. Acta Scientiarum Polonorum Hortorum Cultus 12(4): 59- 
66.

Hartmann HT, Kester DE, Davies FT, Geneve RL 2011. Plant Propagation, Principles and Practices. 8th Ed., Prentice Hall Inc., New Jersey, 880pp.

Hassanpour H, Yousef H, Jafar H, Mohammad A 2011. Antioxidant Capacity and Phytochemical Properties of Cornelian Cherry (Cornus mas L.) Genotypes in Iran. Scientia Horticulturae 129(3): 459-463.

Hocoğlu C 2013. Bazı Önişlemlerin Kızılcık (Cornus mas) ve Yabani Kiraz (Prunus avium) Tohumlarının Çimlenmesi Üzerine Etkisi. Artvin Çoruh Üniversitesi Fen Bilimleri Enstitüsü Orman Mühendisliği Anabilim Dalı, Yüksek Lisans Tezi, 31sy.

Hosseinpour-Jaghdani F, Shomali T, GholipourShahraki S, Rahimi-Madiseh M, Rafieian-Kopaei M 2017. Cornus mas: A Review on Traditional Uses and Pharmacological Properties. Journal of Complementary and Integrative Medicine 14(3): 128.

Husen A, Pal M 2006. Variation in Shoot Anatomy and Rooting Behaviour of Stem Cuttings in Relation to Age of Donor Plants in Teak (Tectona grandis Linn. f.). New Forests 31(1): 57-73.

Ivanicka J, Cvopa J 1977. Propagation of Dogwood (Cornus mas L.) by Softwood and Semi-Hardwood Cuttings. Gartenbauwissenchaft 42(4): 169-171.

Kalkışım Ö 1997. Kızılcıkta (Cornus mas L.) Aşı Kaynaşması ile Çelik Köklenmesinin Anatomik ve Histolojik Olarak İncelenmesi Üzerine Bir Araştırma. Yüzüncü Yıl Üniversitesi Fen Bilimleri Enstitüsü Bahçe Bitkileri Anabilim Dalı, Doktora Tezi, 105sy.

Kalyoncu H 1996. Konya Yöresindeki Kızılcık (Cornus mas L.) Tiplerinin Bazı Özellikleri ve Farklı Nem Ortamlarındaki Köklenme Durumu Üzerine Bir Araştırma. Selçuk Üniversitesi Fen Bilimleri Enstitüsü Tarımsal Yapılar ve Sulama Anabilim Dall, Doktora tezi, 138sy.

Kalyoncu H, Ecevit FM 1995. Farkl Nem Seviyelerinin Kızılcık (Cornus mas L.) Yeşil Çeliklerinde Köklenme Üzerine Etkileri. Türkiye II. Ulusal Bahçe Bitkileri Kongresi 3-6 Ekim 1995, Adana.

Kalyoncu H, Ersoy N, Yılmaz M 2008. Kızılcık (Cornus mas L.) Yeşil Uç Çeliklerinin Köklenmesi Üzerine Farklı IBA Dozları ve Nem Seviyelerinin Etkileri. Selçuk Üniversitesi Ziraat Fakültesi Dergisi 22(46): 62-67.

Kamaluddin M, Ali M 1996. Effects of Leaf Area and Auxin on Rooting and Growth of Rooted Stem Cuttings of Neem. New Forests 12(1): 11-18.

Kaşka N, Yılmaz M 1974. Bahçe Bitkileri Yetiştirme Tekniği. (Hudson T. Hartman ve Dale E.
Kester"den Çeviri), Çukurova Üniversitesi Ziraat Fakültesi Yayınları, Ders Kitabı No: 52, Adana, 611 sy.

Marković M, Grbić M, Djukić M 2013. Effects of Cutting Type and A Method of IBA Application on Rooting of Softwood Cuttings from Elite Trees of Cornelian Cherry (Cornus mas L.) from Belgrade Area. International Scientific Conference at 85th Anniversary of Bulgarian Academy of Sciences 1-2 October 2013, Sofia, Bulgaria.

Mratinić E, Akšić MF, Rakonjac V, Miletić R, Žikić M 2015. Morphological Diversity of Cornelian Cherry (Cornus mas L.) Populations in the Stara Planina Mountain, Serbia. Plant Systematics and Evolution 301(1): 365-374.

Pırlak L 1997a. Bazı Uygulamaların Kızılcık (Cornus mas L.) Tohumlarının Çimlenme Üzerine Etkileri. Atatürk Üniversitesi Ziraat Fakültesi Dergisi 28(2): 212-221.

Pırlak L 1997b. Kızılcıkta (Cornus mas L.) Çelik Alma Zamanlarının ve IBA Uygulamalarının Yeşil Çeliklerin Köklenmeleri Üzerine Etkileri. Atatürk Üniversitesi Ziraat Fakültesi Dergisi 28(3): 369380.

Pirlak, L. 2000. Effects of Different Cutting Times and IBA Doses on the Rooting Rate of Hardwood Cuttings of Cornelian Cherry (Cornus mas L.). Journal of Aegean Agricultural Research Institute 10(1): 122-134.

Seeram NP, Schutzki R, Chandra A, Nair MG 2002. Characterization, Quantification, and Bioactivities of Anthocyanins in Cornus Species. Journal of Agricultural and Food Chemistry 50(9): 2519-2523.

Yavaş MA 2000. Tokat'ta Kizılcık'in (Cornus mas L.) Yeşil ve Odun Çelikleri ile Çoğaltılması Üzerine Bir Araştırma. Gaziosmanpaşa Üniversitesi Fen Bilimleri Enstitüsü Bahçe Bitkileri Anabilimdalı, Yüksek Lisans Tezi, Tokat, 56sy.

Yavuz Ç 2015. Malatya Ili'nden Selekte Edilen Bazı Kızılcık (Cornus mas L.) Genotiplerinde Farklı IBA Uygulamalarının Yeşil Çeliklerin Köklenmesi Üzerine Etkileri. Kahramanmaraş Sütçü İmam Üniversitesi Fen Bilimleri Enstitüsü, Bahçe Bitkileri Anabilimdalı, Yüksek Lisans Tezi, Kahramanmaraş, 37sy.

Yıldız K, Çekiç Ç, Güneş M, Özgen M, Özkan Y, Akça Y, Gerçekçioğlu R 2009. Farklı Dönemlerde Alınan Kara Dut (Morus nigra L.) Çelik tiplerinde köklenme başarısının belirlenmesi. Gaziosmanpaşa Üniversitesi Ziraat Fakültesi Dergisi 26(1): 1-5.

Yılmaz KU, Ercişli S, Zengin Y, Şengül M, Kafkas EY 2009. Preliminary Characterisation of Cornelian Cherry (Cornus mas L.) Genotypes for Their Physico-Chemical Properties. Food Chemistry 114(2): 408-412. 